\title{
A Coupled One-Dimensional Sea Ice-Ocean Model
}

\author{
Peter Lemke \\ Max-Planck-Institut für Meteorologie, Hamburg, Federal Republic of Germany
}

\begin{abstract}
A prognostic one-dimensional mixed layer-pycnocline model describing the vertical structure of the upper ocean is coupled to a thermodynamic sea ice model. The coupled prognostic model is compared with the more usual sea ice model overlying a fixed mixed layer with constant oceanic heat flux and is then applied to investigate the effect of temporal and regional variations of the entrained oceanic heat flux on the sea ice cover in both polar regions. In the southern ocean a standard simulation is compared with two perturbation experiments which both describe the occurrence of a polynya. In the Arctic Ocean the effect of possible Soviet river diversions is investigated. Finally, the response of the coupled model to paleoclimatic forcing and boundary conditions is presented.
\end{abstract}

\section{INTRODUCTION}

In sea ice models the vertical heat flux from the deep ocean into the mixed layer is generally prescribed as constant in space and time. Assumed values range from $2 \mathrm{~W} / \mathrm{m}^{2}$ for the Arctic up to $20 \mathrm{~W} / \mathrm{m}^{2}$ for the Antarctic [Parkinson and Washington, 1979; Hibler, 1979; Pollard et al., 1983; Semtner, 1984a]. In a study by Hibler [1984] on the Weddell Sea ice, the vertical oceanic heat flux was taken to be proportional to the atmospheric freezing rate.

In this paper a thermodynamic sea ice model similar to the simplest model of Parkinson and Washington [1979] is coupled to a seasonally varying one-dimensional mixed layerdeep ocean model in which the vertical oceanic heat flux is described prognostically through the entrainment heat flux into the mixed layer. It is shown that the temporal and spatial variations of the prognostic oceanic heat flux are significant and cannot be satisfactorily approximated as constant. The mixed layer-deep ocean model is adapted from Lemke and Manley [1984] and is similar to that of Pollard et al. [1983]. Although Pollard et al. [1983] also couple a time-dependent mixed layer to the sea ice model, their principal results (except for a short note in the appendix) were obtained by setting the vertical oceanic heat flux constant in space and time.

In our paper, sea ice and the ocean are completely coupled. The seasonal variation of sea ice computed using a prognostic mixed layer with time-dependent vertical oceanic heat flux differs markedly from the case of a fixed mixed layer with constant oceanic heat flux. This is in contrast to the results of Pollard et al. [1983], which were insensitive to the kind of mixed layer model used, presumably because the vertical oceanic heat flux in their paper was still specified as constant.

It is shown here that the vertical oceanic heat flux is highly variable in space and time, being largest (up to $13 \mathrm{~W} / \mathrm{m}^{2}$ in the southern ocean) near the Antarctic continent, where the oceanic stratification is weakest. From late winter on, when the mixed layer depth is near its maximum, and during the retreat phase in spring and early summer the vertical oceanic heat flux is negligible. The seasonal variation of the mixed layer depth (heat storage) and of the oceanic heat flux cause a delay in the freeze-up and a reduction of the maximum ice extent. The excessive ice extent was a problem in earlier simple sea ice models and was overcome by suitable tuning of the leads and albedo parameterizations.

Copyright 1987 by the American Geophysical Union.

Paper number 7 C0627.

0148-0227/87/007C-0627\$05.00
Recently, Hibler and Bryan [1987] have presented results of a coupled three-dimensional diagnostic ocean circulation and sea ice model. In this model the oceanic heat flux into the upper layer of fixed depth is produced by advective effects and by convective overturning, the latter effect being a sporadic event which takes place only if the model density stratification is unstable. In our one-dimensional model, advective effects are simply parameterized by net heat and salt sources, which describe the divergences of the horizontal transports. The oceanic heat flux used to melt sea ice is maintained by continuous entrainment during the deepening of the upper mixed layer.

The one-dimensional prognostic sea ice-ocean model described in section 2 is applied in section 3 to the southern ocean and the Arctic Ocean. For the southern ocean the standard experiment (stationary seasonal cycle) is compared with two polynya experiments. In the first experiment a destruction of the ice cover is produced by a destabilization of the water column through excessive entrainment of dense warm water above a warm cell, which significantly raises the pycnocline [Gordon and Huber, 1984]. The second mechanism for creating a polynya is the destabilization of the oceanic stratification due to excess freezing in a region of divergent sea ice motion. In the Arctic Ocean the effect of a reduction of the freshwater flux due to Soviet river diversion is investigated. Finally, the response of the coupled sea ice-ocean model is investigated for changes in boundary conditions relevant for paleoclimatic studies, such as reduced solar radiation, smaller surface air temperature, colder deep ocean temperatures, or increased freshwater flux due to melting of ice sheets.

\section{THE MODEL}

\subsection{Mixed Layer-Pycnocline Model}

The one-dimensional mixed layer-pycnocline model used here is similar to that of Lemke and Manley [1984], extended to include salinity and temperature. The entrainment parameterization is slightly modified. The vertical structure of the two layer ocean model is shown in Figure 1. Temperature and salinity are constant within the mixed layer and show an exponential behavior within the pycnocline.

$$
\begin{array}{llrl}
T(z) & =T & 0>z>-h \\
S(z) & =S & & \\
T(z) & =T_{\infty}+\left(T-T_{\infty}\right) \exp \left[(z+h) / d_{\mathrm{T}}\right] & & -h>z>-h_{b} \\
S(z) & =S_{\infty}+\left(S-S_{\infty}\right) \exp \left[(z+h) / d_{S}\right] &
\end{array}
$$




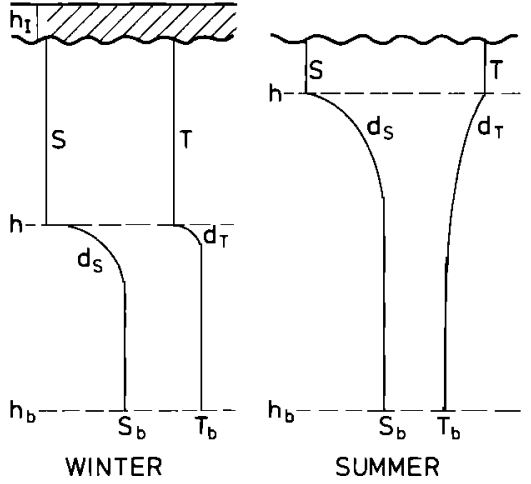

Fig. 1. Vertical structure of the mixed layer-pycnocline model.

The prognostic variables are the mixed layer temperature $T$ and salinity $S$, the mixed layer depth $h$, the $e$-folding depths of the thermocline $d_{T}$ and halocline $d_{S}$, and the sea ice thickness $h_{l}$. The prognostic equations of the mixed layer-pycnocline model are derived from the conservation of heat and salt, potential energy considerations and a parameterization for the entrainment heat and salt fluxes. The lower level of the model $\left(h_{b}\right)$ is set at $3000 \mathrm{~m}$. Generally, the scale depths of the thermocline and halocline $d_{T}, d_{S} \ll h_{b}-h$, so that $T_{b}=T\left(-h_{b}\right) \approx T_{\infty}$ and $S_{b}=S\left(-h_{b}\right) \approx S_{\infty} . T_{b}$ and $S_{b}$ are considered as given boundary conditions.

With the above assumption the salt content $H_{s}$ of the system is given by

$$
H_{S}=\left(S-S_{b}\right)\left(h+d_{S}\right)+S_{b} h_{b}
$$

From the salt balance we infer that the change of salt content is balanced by the salt flux at the sea surface, $Q_{s}$, and the upwelling $W$,

$\dot{H}_{s}=\dot{S}\left(h+d_{s}\right)+\left(S-S_{b}\right)\left(\dot{h}+d_{s}\right)=Q_{s}+W\left(S_{b}-S\right)$

The upwelling term represents the net effect of the oceanic circulation, i.e., the divergence of the horizontal salt transport, required to balance the excess of precipitation over evaporation at high latitudes. For the heat content $H_{T}$ we find similarly from heat conservation

$\dot{H}_{T}=\dot{T}\left(h+d_{T}\right)+\left(T-T_{b}\right)\left(h+d_{T}\right)=Q_{T}+W\left(T_{b}-T\right)$

where $Q_{T}$ is the surface heat flux.

In mixed layer modeling it is usually assumed that the rate of change of the mixed layer salinity and temperature is dominated by the appropriate surface and entrainment fluxes

$$
\begin{aligned}
& \dot{S}=\left(Q_{S}+B_{S}\right) / h \\
& T=\left(Q_{T}+B_{T}\right) / h
\end{aligned}
$$

$B_{S}$ and $B_{T}$ represent the entrainment fluxes of salt and heat, respectively. These fluxes are parameterized in terms of a turbulent length scale $\delta$ and the entrainment velocity $W_{e}$. This represents a translation of the Kraus-Turner type parameterization for a discontinuous profile to our case of a continuous profile with a sharply discontinuous gradient at $z=-h$.

Consider an entrainment zone of thickness $\delta$ which is not resolved in our model. This zone is characterized by a mean temperature $T^{*}$ and salinity $S^{*}$ which are given by

$$
T^{*}=\frac{1}{\delta} \int_{-h-\delta}^{-h} T(z) d z
$$

$$
S^{*}=\frac{1}{\delta} \int_{-h-\delta}^{-h} S(z) d z
$$

Inserting (1), the integration yields

$$
\begin{aligned}
T^{*}=T_{b}+\left(T_{b}-T\right) d_{T}[ & \left.\exp \left(-\delta / d_{T}\right)-1\right] / \delta \\
& \approx T+\frac{1}{2}\left(T_{b}-T\right) \delta / d_{T} \quad \delta \ll d_{T} \\
S^{*}=S_{b}+\left(S_{b}-S\right) d_{S}[ & \left.\exp \left(-\delta / d_{S}\right)-1\right] / \delta \\
& \approx S+\frac{1}{2}\left(S_{b}-S\right) \delta / d_{S} \quad \delta \ll d_{S}
\end{aligned}
$$

The entrainment salt and heat fluxes are now parameterized as

$$
\begin{aligned}
B_{T} & =\left(T^{*}-T\right) W_{e} \\
B_{S} & =\left(S^{*}-S\right) W_{e}
\end{aligned}
$$

The closure for mixed layer models is generally taken from potential energy considerations. Wind and ice keel stirring provide the energy $\tilde{K}$ needed to balance the increase of the potential energy due to the surface and entrainment fluxes, $Q$ and $B$, respectively. In wintertime, convection provides additional energy for the deepening of the mixed layer. Other turbulent kinetic energy sources besides wind stress and convection are neglected. We assume that below the mixed layer there is always enough turbulence in the pycnocline to provide the energy needed to maintain the exponential profile.

From these considerations the potential energy balance for the entrainment process is given by [Niiler and Kraus, 1977; Lemke and Manley, 1984]

$$
\tilde{K}-\varepsilon=\frac{h}{2} g(B-Q)
$$

where $g$ is the gravitational acceleration and $\varepsilon$ is a dissipation term which is parameterized in terms of the active turbulence generating processes: wind and ice keel stirring, and convection. The surface and entrainment buoyancy fluxes, $Q$ and $B$, respectively, are determined from

$$
\begin{aligned}
& Q=\beta Q_{S}-\alpha Q_{T} \\
& B=\beta B_{S}-\alpha B_{T}
\end{aligned}
$$

where $\alpha$ and $\beta$ represent the expansion coefficients of the density with respect to temperature and salinity.

Inserting (11), (12), (14), and (15) into (13) yields for the entrainment velocity

$$
W_{e}=\frac{2 K D_{1}+h Q D_{2}}{h E}
$$

where $K=\widetilde{K} / g, E=\beta\left(S^{*}-S\right)-\alpha\left(T^{*}-T\right)$ and $\left(1-D_{1}\right)$ and $\left(1-D_{2}\right)$ represent the (depth-dependent) dissipation of mechanical and convective energy input at the sea surface. This is assumed to be exponential,

$$
\begin{gathered}
D_{1}=\exp \left(-h / h_{w}\right) \\
D_{2}=\exp \left(-h / h_{c}\right) \quad Q>0 \\
D_{2}=1 \quad Q<0
\end{gathered}
$$

The scale depths of dissipation $h_{w}$ and $h_{c}$ are determined together with the turbulent length scale $\delta$ from a least squares fit of the salinity part of the model to observations obtained during the Arctic Ice Dynamics Joint Experiment (AIDJEX). Using the technique of Lemke and Manley [1984], the optimal 
values of the model parameters were obtained as $\delta=8 \mathrm{~m}$, $h_{w}=7 \mathrm{~m}$, and $h_{c}=50 \mathrm{~m}$. As in the work of Lemke and Manley [1984], the model results are not very sensitive to moderate changes of these parameters. In order to allow for deep convection in case of a weak stratification, the dissipation of convective energy is taken to be constant for $h>h_{\max }$ $=50 \mathrm{~m}$, such that $D_{2}=\max \left[\exp \left(-h / h_{c}\right), \exp \left(-h_{\max } / h_{c}\right)\right]$.

Rearranging (3), (4), (5), (6), (11), and (12) leads to

$$
\begin{gathered}
\dot{S}=\frac{Q_{S}}{h}+\frac{S^{*}-S}{h} W_{e} \\
\dot{T}=\frac{Q_{T}}{h}+\frac{T^{*}-T}{h} W_{e} \\
d_{S}=\frac{d_{S}}{S_{b}-S} \dot{S}+\left(\frac{S^{*}-S}{S_{b}-S}-1\right) W_{e} \\
d_{T}=\frac{d_{T}}{T_{b}-T} \dot{T}+\left(\frac{T^{*}-T}{T_{b}-T}-1\right) W_{e}
\end{gathered}
$$

where the change of the mixed layer depth $h$ is given by the entrainment velocity $W_{e}$ and the upwelling velocity $W$,

$$
h=W_{e}-W
$$

Equations (16) and (19) through (23) apply only for the deepening of the mixed layer (entrainment phase, $W_{e}>0$ ). During the period of increased heating (melting), the stress-induced energy at the surface is generally insufficient to overcome the stabilizing effect of the surface buoyancy flux $\left(W_{e}<0\right)$. In this case the mixed layer retreats to an equilibrium depth $\hat{h}$ given diagnostically by the Monin-Obukhov length, which is determined by (16) with $W_{e}=0$ or

$$
2 K D_{1}+h Q=0
$$

Changes of the surface temperature and salinity during the retreat phases are determined from (19) and (20), respectively, with $W_{e}=0$. The thermocline and halocline variables $d_{T}$ and $d_{s}$, finally, are determined from the conservation of heat and salt (equations (3) and (4)), respectively.

With given fluxes at the sea surface and with boundary conditions at $z=-h_{b}$ the evolution of the mixed layerpyconocline model can now be calculated. For the prescription of the kinetic energy input $\tilde{K}$ we follow the AIDJEX analysis, where $\tilde{K}$ was expressed in terms of the sea ice velocity $u$, relative to the ocean below the frictional layer [McPhee and Smith, 1976; Lemke and Manley, 1984],

$$
\tilde{K}=C_{w}|\mathbf{u}|^{3} \cos \gamma
$$

where $\gamma$ is the frictional turning angle, found to be about $24^{\circ}$, and the drag coeflicient $C_{w}$ was estimated to be $5 \times 10^{-3}$. The surface salt flux $Q_{S}$ is given by the net surface freshwater flux $F$, determined by the excess of precipitation over evaporation and by drifting snow and sea ice, and by the rate of change of the sea ice thickness $h_{l}$,

$$
Q_{s}=-F S+\left(S-S_{I}\right) h_{I} \rho_{I} / \rho_{W}
$$

where $S_{I}$ is the salinity of sea ice, taken to be $5 \%$, and $\rho_{I}$ and $\rho_{W}$ are the densities of sea ice and water, respectively.

\subsection{Sea Ice}

Since the main purpose of this paper is to describe the interaction of the sea ice cover with the ocean through the entrainment process, we have used a simple one-layer sea ice model without lead parametrization and prognostic snow cover. The sea ice growth rates in (26) are calculated using Semtner's [1976] thermodynamic sea ice model in conjunction with a surface heat budget calculation similar to that of Parkinson and Washington [1979]. The effects of snow cover are approximated by allowing the ice surface albedo to be that of snow when the calculated surface temperature is below freezing and that of snow-free ice when the surface temperature of the ice is at the melting point.

\subsection{Sea Ice-Ocean Coupling}

The determination of the surface buoyancy flux $Q$ differs a little from the more straightforward calculation in the open ocean [see Niiler and Kraus, 1977]. In contrast to low latitudes and mid-latitudes, the pycnocline under polar sea ice is generally warmer than the mixed layer. Therefore in ice covered oceans the interaction between the heat and salt budgets is essential. When entrainment takes place owing to enhanced winds or freezing (brine convection), warm water is mixed into the upper layer. This heat is used to melt sea ice, thereby modifying the surface heat and salt fluxes; i.e., the surface buoyancy flux is partly determined through the entrainment velocity.

The heat flux at the sea ice-ocean interface, $Q_{T}$, is given by the entrainment heat flux (equation (11)), which is lost to the melting of ice. We assume that the mixed layer temperature remains at the freezing point as long as sea ice is present. From (20) with $\dot{T}=0$ we find

$$
Q_{T}=-B_{T}=-\left(T^{*}-T\right) W_{e}
$$

The total surface salt flux is accordingly determined by the freezing of ice due to heat loss to the atmosphere, $Q_{T}{ }^{A}$, and by melting of ice due to the oceanic heat flux (equation (27)), and by the net surface freshwater flux $F$.

$$
\begin{aligned}
Q_{S} & =\left(S-S_{I}\right) h_{I} \frac{\rho_{I}}{\rho_{W}}-F S \\
& =\left(S-S_{I}\right) \frac{\rho_{I}}{\rho_{W}}\left[Q_{T}{ }^{A} /\left(\rho_{I} L\right)-c\left(T^{*}-T\right) W_{e} /\left(\rho_{I} L\right)\right]-F S
\end{aligned}
$$

where $L$ is the latent heat of fusion and $c=4.26 \times 10^{6} \mathrm{~J} / \mathrm{m}^{3}$ K. $Q_{T}{ }^{A}$, the atmospheric freezing rate, is calculated from the thermodynamic sea ice model mentioned earlier. Effects of sea ice dynamics [Hibler, 1979] will be included in a later publication.

Equations (27) and (28) show that the total surface buoyancy flux $Q$, determined from (14), includes two terms which are proportional to the entrainment velocity $W_{e}$. Together with (11), (12), (13), and (15) this leads to a reformulation of the entrainment rate $W_{e}$,

$$
W_{e}=\frac{2 K D_{1}+h Q^{*} D_{2}}{h\left(E+E^{*}\right)}
$$

where

$$
\begin{gathered}
E^{*}=\left[\frac{\beta c}{\rho_{W} L}\left(S-S_{I}\right)-\alpha\right]\left(T^{*}-T\right) \\
Q^{*}=\frac{\beta}{\rho_{W} L}\left(S-S_{I}\right) Q_{T}^{A}-\beta F S
\end{gathered}
$$

$Q^{*}$ contains now only the atmospherically induced freezing 
term of (28). Since $E^{*}$ is positive, the entrained oceanic heat flux always leads to a reduction of the entrainment rate.

Equations (27) to (31) apply only for the ice-covered ocean. In the open ocean adjacent to the sea ice edge, $Q_{T}$ is determined from the surface energy balance, and $Q_{s}$ is specified from evaporation minus precipitation (equation (26)).

\section{Results}

The coupled sea ice-ocean model described above is applied first to the southern ocean. A standard run using a prognostic mixed layer model is compared with a fixed mixed layer calculation, and two polyna experiments are discussed. We consider then the effect of possible Soviet river diversions for the Arctic Ocean. Finally, the response of the coupled model to paleoclimatic changes in the boundary and forcing conditions is investigated. The standard forcing conditions, surface air temperature and surface winds, are taken from Oort [1983] and are linearily interpolated to 1 -day intervals and a $1^{\circ}$ latitude grid. Because of lack of more detailed data, the annual net surface freshwater flux $F$ (= precipitation minus evaporation and drifting snow and ice) is taken to be constant in space and time $(0.35 \mathrm{~m} /$ year $)$. For the same reasons the kinetic energy input $K$ due to wind stress and ice keel stirring is also taken as constant corresponding to a sea ice velocity of $0.15 \mathrm{~m} / \mathrm{s}$ for the southern ocean and $0.1 \mathrm{~m} / \mathrm{s}$ for the Arctic [see Lemke and Manley, 1984]. The surface friction velocities are accordingly $0.9 \mathrm{~cm} / \mathrm{s}$ and $0.6 \mathrm{~cm} / \mathrm{s}$. The upwelling velocity $W$ is also assumed to be constant, namely, $10^{-7} \mathrm{~m} / \mathrm{s}$ in the Arctic basin and $5 \times 10^{-7} \mathrm{~m} / \mathrm{s}$ in the southern ocean.

\subsection{Southern Ocean}

In the southern ocean the coupled sea ice-mixed layerpycnocline model is applied along a north-south section extending from $55^{\circ} \mathrm{S}$ to $70^{\circ} \mathrm{S}$ latitude. The deep ocean temperature (salinity) increases (decreases) from $0.5^{\circ} \mathrm{C}(34.75 \%)$ at $70^{\circ} \mathrm{S}$ to $3.5^{\circ} \mathrm{C}(34.45 \%)$ at $55^{\circ} \mathrm{S}$. A typical seasonal response of the model variables for $64^{\circ} \mathrm{S}$ is shown in Figure 2 (solid lines; day 1 represents January 1). During summer, when there is no ice and the mixed layer temperatures rises from freezing $\left(-1.9^{\circ} \mathrm{C}\right)$ up to $1^{\circ} \mathrm{C}$, the mixed layer salinity and depth increases only slightly. With the occurrence of sea ice around day 175 there is a strong deepening of the mixed layer due to the brine rejection and subsequent pronounced increase of the surface salinity. With the beginning of spring around day 305 , when the ice starts to melt, the mixed layer suddenly retreats to its minimum depth because of the considerable freshwater flux at the surface. The pynocline $d_{S}$ is rather sharp during most of the year except for the retreat phase, where $d_{s}$ increases significantly. The thermocline thickness $d_{T}$, which is less dynamically important, ranges from $50 \mathrm{~m}$ to $250 \mathrm{~m}$. The modeled amplitudes of the mixed layer properties agree with observations in the Antarctic seasonal sea ice zone [Foster and Carmack, 1976; Gordon and Huber, 1984].

A north-south section of the mixed layer depth at the end of winter (day 295) and in spring (day 365), and the maximum mixed layer depth in wintertime, is displayed in Figure 3. Because of the strong brine convection during winter, the mixed layer depth under the sea ice cover is seen to be deeper than that in the open ocean. During spring, however, it is shallower under the sea ice, since the surface freshwater flux due to the melting of sea ice is more effective than the heat flux.

In earlier sea ice studies [Hibler, 1979; Parkinson and Washington, 1979; Hibler and Ackley, 1983; Semtner, 1984a] the
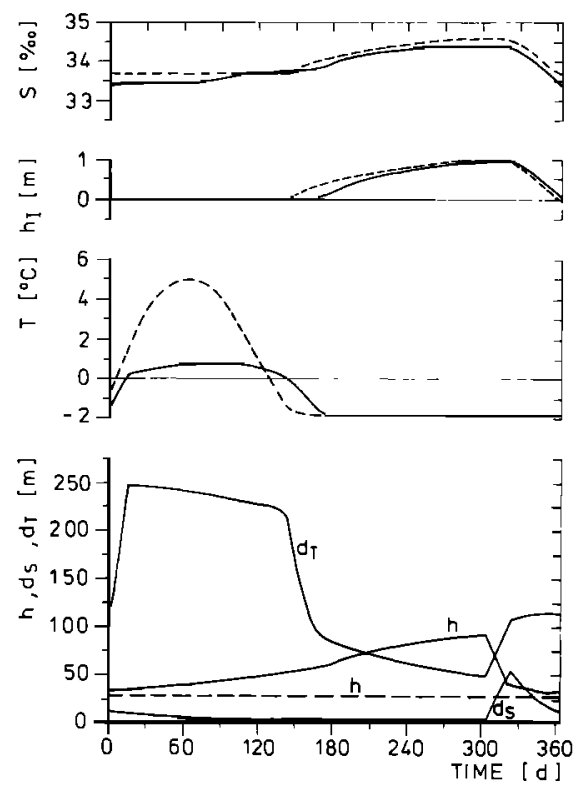

Fig. 2. Equilibrium seasonal response of the model sea ice thickness $h_{f}$, the mixed layer temperature $T$, Salinity $S$, and depth $h$ and the halocline $\left(d_{S}\right)$ and thermocline $\left(d_{T}\right)$ scales in the southern ocean at $64^{\circ} \mathrm{S}$ for the prognostic (solid lines) and the fixed mixed layer depth (dashed lines) cases.

ocean was generally represented by a constant depth mixed layer which received a constant heat flux from the deep ocean, generally in the range from 2 to $20 \mathrm{~W} / \mathrm{m}^{2}$. A corresponding calculation is shown in Figure 2 (dashed lines) for the case $h=30 \mathrm{~m}$ (with $d_{S}=d_{T}=0$ ) and a constant deep ocean heat flux of $7 \mathrm{~W} / \mathrm{m}^{2}$.

There is a significant difference in the phase of the seasonal cycle of the sea ice thickness. In the fixed mixed layer case the freezing occurs about 1 month earlier and the melting occurs about 10 days earlier than in the prognostic mixed layer case. Figure 4 shows that in the prognostic mixed layer model the amplitude of the seasonal cycle of the sea ice extent is substantially reduced (by $4^{\circ}$ latitude), but the sea ice thickness at a given latitude at the end of winter is comparable for latitudes south of $62^{\circ} \mathrm{S}$ (Figure 5).

In contrast to the results of Pollard et al. [1983] there is a significant difference in the seasonal sea ice response for the different mixed layer models. The reason lies in the space and time dependence of the entrained oceanic heat flux, which was held constant by Pollard et al. [1983]. The strong variations of

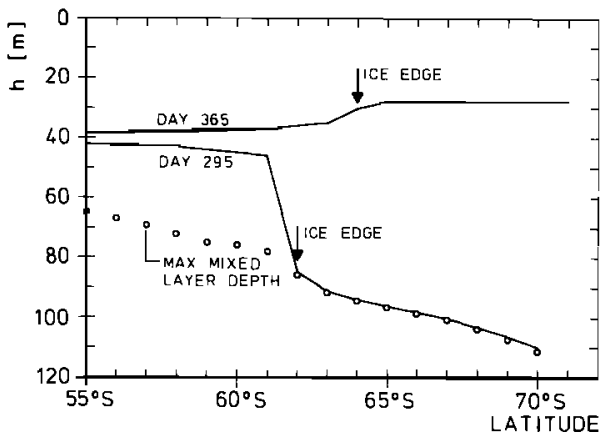

Fig. 3. North-south section of the mixed layer depth in the southern ocean at the end of winter (day $295=$ October 22) and in spring (day $365=$ December 31 ). Also shown is the maximum winter mixed layer depth. 


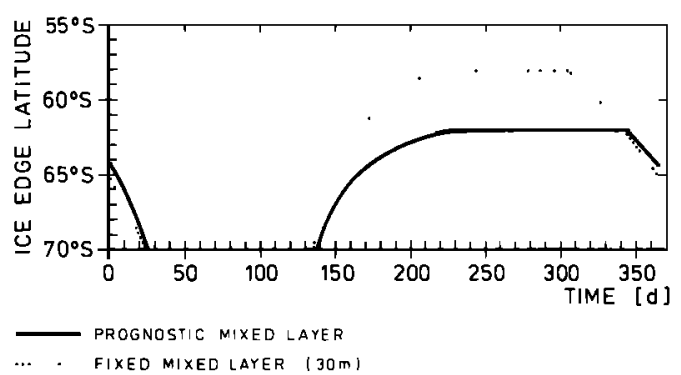

Fig. 4. Equilibrium seasonal response of the sea ice edge in the southern ocean for the prognostic (solid line) and the fixed mixed layer depth (dotted line) models

the entrainment heat flux under the ice cover with latitude and time are displayed in Figure 6.

At low latitudes near the ice edge the maximum entrained oceanic heat flux under the ice is largest during the onset of winter, when the entrainment velocity itself is largest. The occurrence of this maximum effectively reduces and delays the advance of the sea ice. This effect was missing in earlier Antarctic sea ice studies, and the computed winter ice extent was accordingly too large. The increased prognostic oceanic heat flux during the onset of winter and the vanishing heat flux during the retreat of the mixed layer explain the phase shift observed in Figure 2. At higher latitudes there is a second maximum at the end of winter, when the thermocline is rather sharp and upward heat diffusion is more important than entrainment. (The thermocline thickness $d_{T}$ is never allowed to drop below $5 \mathrm{~m}$. This minimum value for $d_{T}$ is equivalent to introducing some additional diffusion if $d_{T}$ tries to decrease below this value). This double peak structure of the seasonal cycle of the oceanic heat flux agrees well with observations made near Mawson, Antarctica [Allison, 1981]; see Figure 7. At lower latitudes the oceanic heat flux is roughly proportional to the heat loss to the atmosphere (freezing rate) $Q_{T}{ }^{A}$, as was assumed in the experiments of Hibler [1984]. Figure 8 indicates that the entrained oceanic heat flux under sea ice cover during the onset of winter (day 185) is largest at the ice edge. At the end of winter (day 275) it is largest near the Antarctic continent. Also, the maximum winter oceanic heat flux is increasing with latitude.

A fixed mixed layer and a constant oceanic heat flux is a rather poor description of the upper ocean characteristics not only under the ice cover but especially for the adjacent open ocean. The crucial variable for the freeze-up is the heat content of the mixed layer. It is important to note here that changes of the heat content are given by variations of the mixed layer temperature and by modifications of the mixed

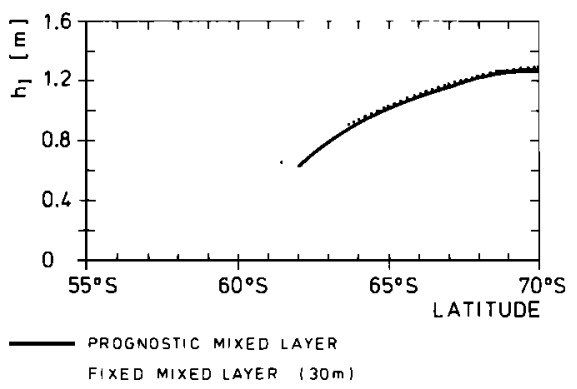

Fig. 5. North-south section of the sea ice thickness in the southern ocean at the end of winter (day $295=$ October 22) for the prognostic (solid line) and the fixed mixed layer depth (dotted line) models.

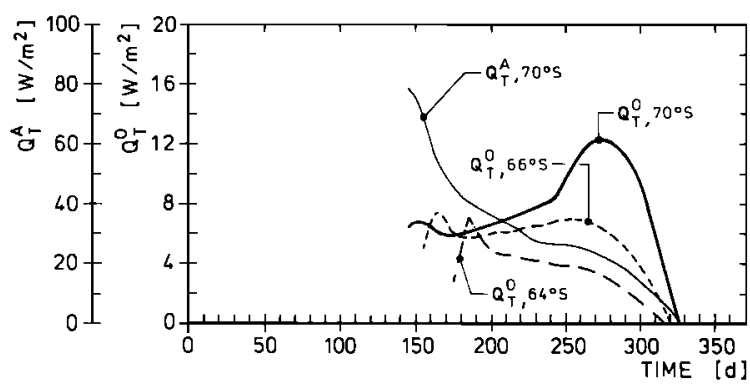

Fig. 6. Mean seasonal cycle in the southern ocean of the entrained oceanic heat flux, $Q_{T}{ }^{\circ}=c B_{T}$, under the sea ice cover (different latitudes) and the atmospheric freezing rate $Q_{T}{ }^{A}\left(70^{\circ} S\right)$.

layer depth, which also changes the thermal inertia of the system. Figure 9 shows a north-south section of the heat loss of the mixed layer to the atmosphere (top curve) and the heat gain of the mixed layer due to deepening (bottom curve). The area between the two curves denotes the change of heat content of the upper layer (north of the ice edge) and the change of the sea ice thickness (south of the ice edge).

In conclusion, it appears that in the open ocean a substantial part (up to $170 \mathrm{~W} / \mathrm{m}^{2}$ close to the ice edge) of the heat loss of the mixed layer to the atmosphere is replaced by the entrainment process. In ice covered regions the heat loss to the atmosphere is significantly reduced owing to the insulating effect of the sea ice.

\subsection{Polynya Experiments}

In the last few years mechanisms have been presented to explain the occurrence of the Weddell polynya observed in winter from 1974 to 1976 [Martinson et al., 1981; Parkinson,
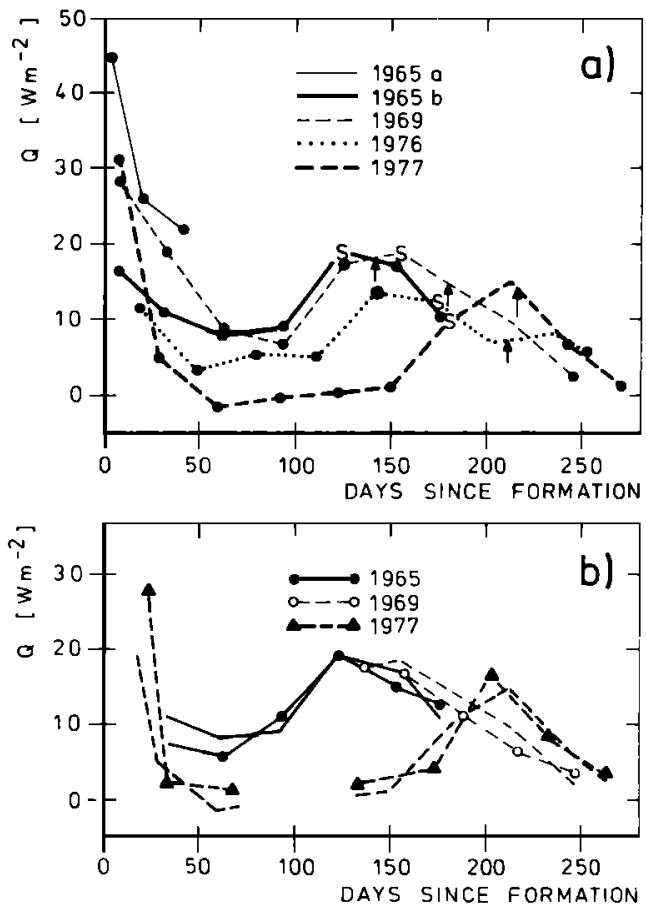

Fig. 7. Heat flux from the ocean to the sea ice at Mawson. (a) Monthly flux values estimated from mean air temperatures and ice growth. The values for September are indicated by $S$, and the times of maximum ice thickness are indicated by arrows. (b) Flux values calculated using measured ice temperature profiles (indicated points) compared to those estimated as for Figure 7a. [from Allison, 1981]. 


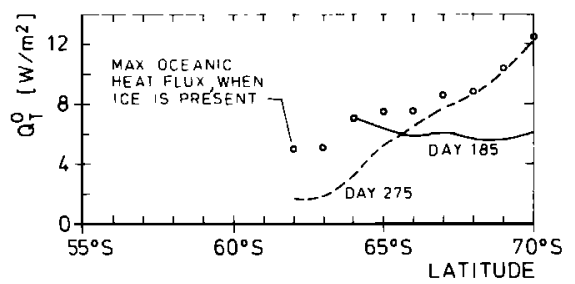

Fig. 8. North-south section of the entrained oceanic heat flux under the sea ice cover in the southern ocean at the beginning (day $185=$ July 4) and end of winter (day $275=$ October 2), together with maximum winter values.

1983; van Ypersele, 1986]. We shall discuss two mechanisms, both of which destabilize the oceanic stratification, allowing stronger entrainment of warm water and a subsequent reduction of the sea ice thickness.

During a cruise in the Weddell Sea, Gordon and Huber [1984] observed large warm subsurface eddies which traveled from the east into the Weddell Sea. These warm cells lifted the mixed layer base significantly and increased the pycnocline temperature, leading to a more intense entrainment of warm and salty water.

In our first polynya experiment we modeled the warm cells by resetting the mixed layer depth to $40 \mathrm{~m}$ for 50 days in the fourth year of integration, at a time when the mixed layer is normally deepening (see the arrow in Figure 10) and by increasing $T_{b}$ by $1^{\circ} \mathrm{C}$. After 50 days, $T_{b}$ is again relaxed to the standard value of $0.6^{\circ} \mathrm{C}$. The surface forcing was taken as the value for $66^{\circ} \mathrm{S}$. Figure 10 shows that although the disturbance by the warm eddy lasts only a short time ( 50 days), the model takes about 10 years of integration time to recover the standard equilibrium seasonal cycle. The largest response of the sea ice thickness takes place in the year after the disturbance. Because of the enhanced entrainment of salty water during the occurrence of the eddy, the mean annual salinity is significantly increased. This leads to stronger entrainment of warm water and a drastic reduction of the sea ice thickness in the following 3 years. The standard equilibrium seasonal cycle is finally reached because of the balancing of net heat and freshwater fluxes and the upwelling terms in (3) and (4).

Another mechanism for creating a polynya is a divergent sea ice drift. This reduces the mean sea ice thickness, leading to excess freezing and a subsequent increase of the surface salinity. In our second polynya experiment we therefore reduce the sea ice thickness for $\mathbf{4 0}$ days in the fourth year to $15 \mathrm{~cm}$, at a time when the ice is normally growing thicker (see the arrow in Figure 11). Although the disturbance lasts only

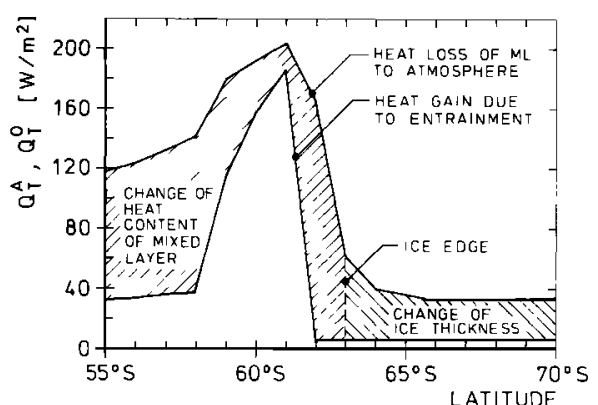

Fig. 9. North-south section of the heat loss of the mixed layer to the atmosphere (top curve) and the heat gain of the upper layer due to entrainment (bottom curve) in the southern ocean on day 205 (July 24).
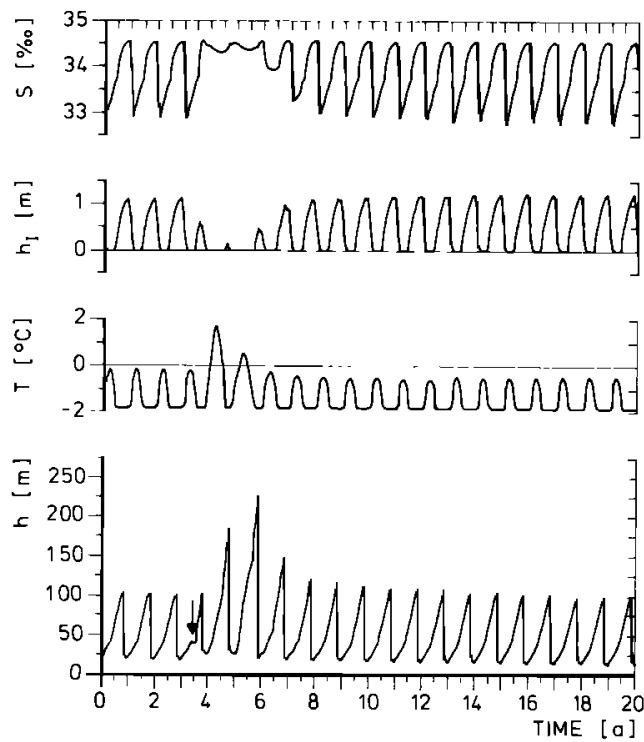

Fig. 10. Results for the model sea ice thickness $h$, and the mixed layer depth $h$, salinity $S$, and temperature $T$ from a 20 -year perturbation experiment. During a 50-day perturbation (see arrow) the mixed layer was reset to $40 \mathrm{~m}$ as soon as it started to entrain deeper, and the deep ocean temperature $T_{b}$ was increased by $1^{\circ} \mathrm{C}$.

for a short time, the response is again felt for several years as in the previous polynya experiment.

In both cases, during the periods of strong deepening of the mixed layer the maximum entrainment heat flux amounts to approximately $150 \mathrm{~W} / \mathrm{m}^{2}$. This is about 20 times the normal upward oceanic heat flux (see Figure 6). The disturbance (warm eddy, ice divergence) is most effective in early winter to midwinter, when the buoyancy fluxes are strong enough to allow deep convection. The occurrence in late winter leads to a moderate response since the buoyancy fluxes and accordingly the convection are weaker. The experiments suggests that the formation of a polynya requires both a sufficiently weak stratification and a sufficiently large disturbance oc-
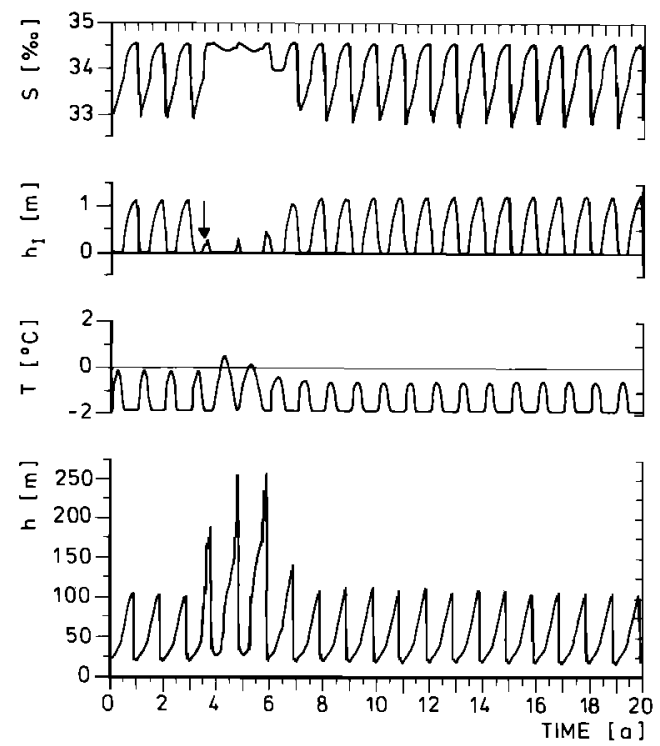

Fig. 11. Results for the model sea ice thickness $h_{I}$ and the mixed layer depth $h$, salinity $S$, and temperature $T$ from a 20 -year perturbation experiment. During a 40-day perturbation (see arrow) the sea ice thickness was reset to $15 \mathrm{~cm}$ as soon as it started to grow thicker. 
curring in early winter. In the case of the warm eddy it is important that the lifting of the pycnocline results in a shallow mixed layer (in our experiment $40 \mathrm{~m}$ ). A reduction of the mixed layer depth from $100 \mathrm{~m}$ to $70 \mathrm{~m}$ has only a minor effect.

\subsection{Arctic Ocean (Soviet River Diversion)}

The mixed layer in the Arctic basin is characterized by low salinity. This is maintained by the large annual runoff from Soviet and Canadian rivers and by the inflow of low-salinity surface water through the Bering Strait. Plans exist in the Soviet Union to divert some on the northward flowing rivers to the south into areas with a strong demand for fresh water. This has led to a discussion of whether a reduction of the Soviet river runoff into the Arctic basin could significantly affect the surface salinity and stratification of the Arctic Ocean and thereby also the sea ice cover. A weaker stratification favors stronger entrainment of the warm Atlantic water below the Arctic pycnocline, which could lead to a melting of sea ice. These effects have been discussed widely in the literature [Aagaard and Coachman, 1975; Holt et al., 1984; Semtner, 1984b; Cattle, 1985].

In this paper the problem is investigated from the point of view of vertical exchange of heat and salt in our onedimensional sea ice-mixed layer-pycnocline model. Effects of horizontal advection are parameterized through an upwelling term (equation (3)). According to the papers cited above, the following freshwater budget is assumed: total Arctic basin river runoff $=0.1 \mathrm{~Sv}$, Bering Strait component $=0.05 \mathrm{~Sv}$, excess of precipitation over evaporation $=0.03 \mathrm{~Sv}$, and sea ice export through the East Greenland Current $=-0.01 \mathrm{~Sv}$. Taking the area of the Arctic basin as $10^{7} \mathrm{~km}^{2}$, these figures imply a net annual freshwater flux of $0.25 \mathrm{~m} /$ year. The model was applied with the appropriate forcing and boundary conditions for $77^{\circ} \mathrm{N}\left(S_{b}=34.8 \%, T_{b}=0.6^{\circ} \mathrm{C}, W=10^{-7} \mathrm{~m} / \mathrm{s}\right)$. After convergence to equilibrium (with $F=0.25 \mathrm{~m} /$ year) two anomaly experiments were conducted, corresponding to a $30 \%$ and $50 \%$ reduction of the Soviet river runoff $(F=0.16$ $\mathrm{m} /$ year and $F=0.09 \mathrm{~m} /$ year, respectively).

Both experiments were integrated for 60 years, and the resulting changes of the annual maximum values of the surface salinity $\Delta S$, of the mixed layer depth $\Delta h$, and of the sea ice thickness $\Delta h_{I}$ are presented in Figure 12 . For a $30 \%$ reduction of the river runofr (top panel) the corresponding change of the maximum winter sea ice thickness is only about $3 \mathrm{~cm}$. The salinity increases by about $1 \%$, and the mixed layer depth increases by $25 \mathrm{~m}$. (The winter values for the standard run are $h_{1}=1.74 \mathrm{~m}, h=55 \mathrm{~m}$, and $S=33.34 \%$ ). A $50 \%$ reduction of the river runofr leads to a more pronounced response. The sea ice thickness is reduced in this case by about $30 \mathrm{~cm}$, and the mixed layer salinity and depth increase by $1.3 \%$ and $130 \mathrm{~m}$, respectively. In both cases the time scale over which changes would occur is about 30 years. Since the Soviet plans correspond to a reduction of the total Arctic river runoff of only a few percent, our model implies that a significant change in the Arctic Ocean characteristics can probably be excluded.

\subsection{Paleoclimatic Experiments}

The surface forcing and deep ocean boundary conditions during earlier paleoclimatic periods are believed to have been quite different from today's values [Shackleton and Pisias, 1985; Duplessy and Shackleton, 1985]. In this section the response of the coupled one-dimensional sea ice-ocean model to changed boundary conditions corresponding to different pos-
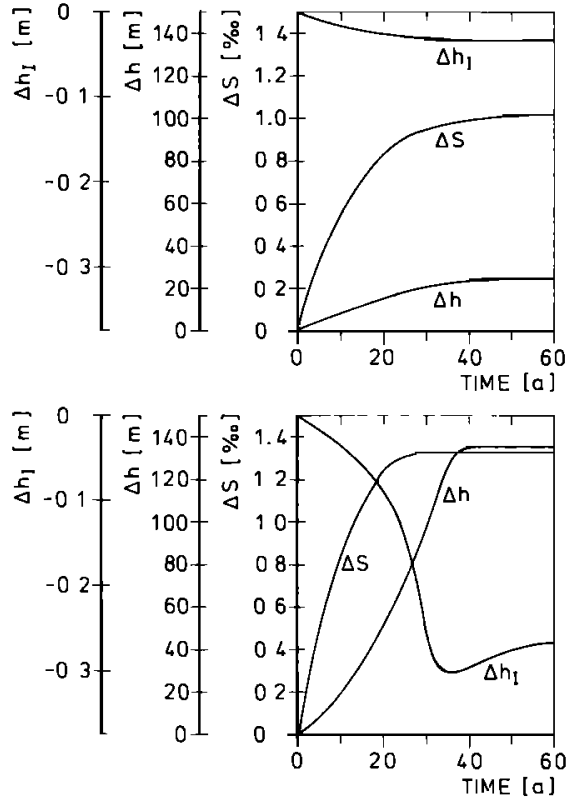

Fig. 12. Response of the sea ice thickness $h_{I}$, the mixed layer salinity $S$, and mixed layer depth $h$ in the Arctic Ocean at $77^{\circ} \mathrm{N}$ to (top) a $30 \%$ and (bottom) a $50 \%$ reduction of the Soviet river runoff.

sible palaeoclimatic epochs is presented. The results are compared with the standard southern ocean experiment discussed in section 3.1.

The deep ocean was probably a few degrees colder during the ice ages [Shackleton et al., 1983]. Therefore in our first experiment the deep ocean temperature $T_{b}$ is set at $0^{\circ} \mathrm{C}$ over the entire grid $\left(55^{\circ} \mathrm{S}-70^{\circ} \mathrm{S}\right)$. All other forcing functions and boundary conditions correspond to the standard experiment. The seasonal response of the sea ice edge is shown in Figure 13 (dashed line), which indicates an advance of the winter sea ice edge by $2^{\circ}$ latitude. But interestingly enough, the sea ice thickness at the end of winter (Figure 14, dashed line) is similar to the standard run, or even slightly reduced south of $62^{\circ} \mathrm{S}$. The reason for this is that the thermocline $\left(d_{T}\right)$ is considerably thinner than it is in the standard run, so that the effective temperature difference $\left(T^{*}-T\right)$ within the entrainment zone is similar to or even larger than in the standard experiment. (The temperature difference $T^{*}-T$ is linearily dependent on the deep ocean temperature, but depends exponentially on the thermocline thickness $d_{T}$; see equation (9)).

At the beginning of the warm interglacials the continental freshwater runoff due to melting ice sheets was considerably

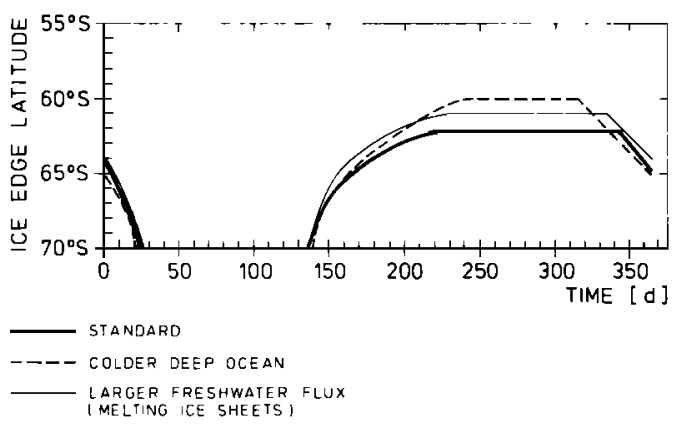

Fig. 13. Equilibrium seasonal response of the sea ice edge in the southern ocean to a colder deep ocean temperature $\left(T_{b}=0^{\circ} \mathrm{C}\right.$ for all latitudes) and larger freshwater flux $(F=1 \mathrm{~m} /$ year). 


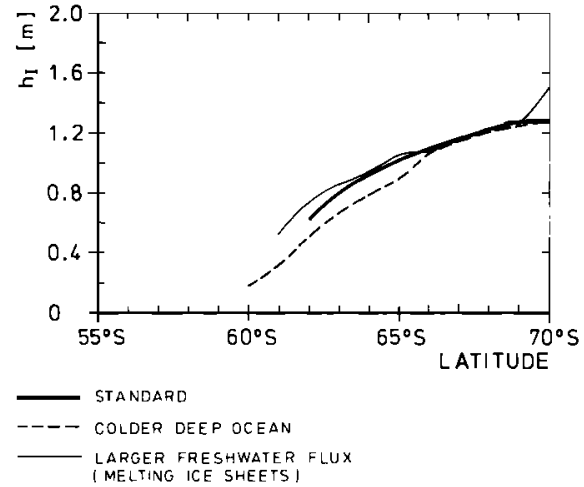

Fig. 14. North-south section of the sea ice thickness at the end of winter (day $295=$ October 22) in the southern ocean for lower deep ocean temperatures $\left(T_{b}=0^{\circ} \mathrm{C}\right)$ and larger freshwater flux $(F=1$ $\mathrm{m} /$ year).

larger than it is today. In our second experiment the annual mean freshwater flux $F$ was therefore assumed to be $F=1$ $\mathrm{m} /$ year. All other forcing functions and boundary conditions remain as they are in the standard run. Figure 13 (thin solid line) indicates that the large freshwater flux leads to a winter sea ice advance by $1^{\circ}$ latitude. The sea ice is slightly thicker than it is in the standard experiment for most latitudes and about $20 \mathrm{~cm}$ thicker at $70^{\circ} \mathrm{S}$, where it survives the summer melt (Figure 14, thin solid line). This feature can be explained by the smaller entrainment heat flux. Because of the stronger stratification (the surface salinity decreases by $1.2 \%$ ) the maximum mixed layer depth $(55 \mathrm{~m})$ is only half that of the standard experiment. Increasing the atmospheric temperatures by $1^{\circ} \mathrm{C}$ over the entire grid together with an increased freshwater flux of $F=1 \mathrm{~m} /$ year yields a sea ice cover similar to the standard case (not shown). We conclude from our model that warm interglacials are probably not characterized by significantly less sea ice cover than is observed today.

Finally, several additional ice age scenarios were investigated: (1) a $2^{\circ} \mathrm{C}$ reduction of the air temperatures; (2) a $10 \%$ reduction of the solar radiation; (3) a simultaneous reduction of the air temperatures by $2^{\circ} \mathrm{C}$, of the solar radiation by $10 \%$, and of the deep ocean temperature of $T_{b}=0^{\circ} \mathrm{C}$ for all latitudes; and (4) a fixed mixed layer depth of $30 \mathrm{~m}$ and a simultaneous reduction of the air temperature by $2^{\circ} \mathrm{C}$ and solar radiation by $10 \%$. All scenarios lead to an advance of the sea ice edge and an increase of the sea ice thickness (Figures 15 and 16 ). A $2^{\circ} \mathrm{C}$ reduction of the air temperature is more effective in increasing the sea ice cover than a $10 \%$ reduction of

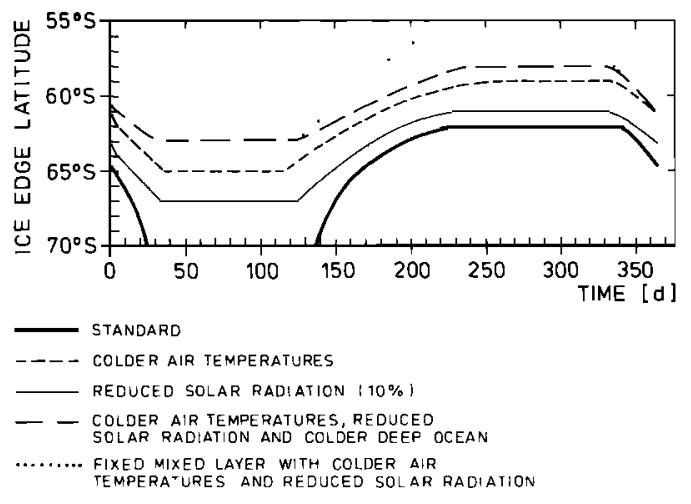

Fig. 15. Same as Figure 13 for different ice age scenarios.

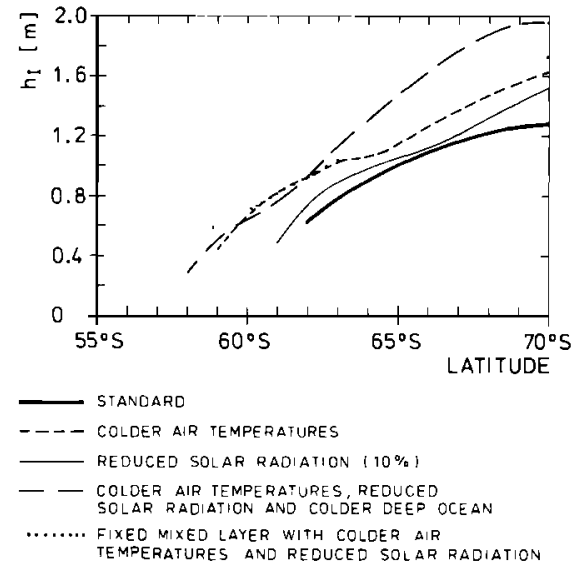

Fig. 16. Same as Figure 14 for different ice age scenarios.

the incoming solar radiation is. The fixed mixed layer depth and constant oceanic heat flux $\left(7 \mathrm{~W} / \mathrm{m}^{2}\right)$ case yields the largest sea ice extent.

\section{ConClusions}

A coupled sea ice-mixed layer-pycnocline model has been presented which can be used for climate studies in conjunction with atmospheric and oceanic general circulation models. The application of the model reveals significant differences compared with existing sea ice models with a fixed mixed layer depth ocean. The model with a prognostic mixed layer depth exhibits a pronounced reduction of the sea ice-covered area, relative to earlier simple thermodynamic sea ice models (which had traditionally overpredicted this variable) and a phase delay in the seasonal cycle of the sea ice thickness. These differences are due to the large regional and temporal variability of the entrained oceanic heat flux.

Experiments with short-time (50 day) disturbances, such as a warm eddy or a divergent sea ice drift, which destabilize the oceanic stratification compared with the normal seasonal conditions, show that such short-lived disturbances are capable of producing an anomalous polynya in several consecutive years.

The investigation of the effect of Soviet river diversions on the Arctic sea ice shows that corresponding to the existing plans of diverting a few percent of the total northward freshwater flux, a significant change of the Arctic Ocean characteristics can probably be excluded.

A series of experiments with different boundary conditions corresponding to different paleoclimatic periods were carried out. An increased surface freshwater flux due to ice sheet melting leads to an advance of the sea ice through the stronger stratification of the upper ocean, which reduces the entrained oceanic heat flux. Additionally increasing the atmospheric surface temperature by $1^{\circ} \mathrm{C}$ results in a sea ice cover similar to the present one. Thus warm interglacials were probably not characterized (during the ice sheet melting) by significantly less sea ice than occurs today. A colder deep ocean, lower atmospheric surface temperatures, and a $10 \%$ reduction of the solar radiation always lead to more sea ice, as one would expect, but it turns out that the response of the sea ice cover to a $2^{\circ} \mathrm{C}$ reduction of the air temperatures is more pronounced than the response to a $10 \%$ reduction of the solar radiation.

Modifications of these results due to the effects of sea ice dynamics and oceanic advection will be investigated in the near future. 
Acknowledgments The author would like to thank K. Hasselmann, W. D. Hibler, D. J. Olbers, E. Maier-Reimer, K. Herterich, J. Imbrie, and N. Shackleton for valuable discussions; U. Kircher for typing the manuscript; and $\mathrm{M}$. Grunert for drafting the figures.

\section{REFERENCES}

Aagaard, K., and L. K. Coachman, Toward an ice free Arctic Ocean, Eos Trans. AGU, 56, 484-486, 1975.

Allison, I., Antarctic sea ice growth and oceanic heat flux, IAHS Publ., 131, 161-170, 1981

Cattle, H., Diverting Soviet rivers: Some possible repercussions for the Arctic Ocean, Polar Rec., 22, 485-498, 1985.

Duplessy, J.-C., and N. J. Shackleton, Response of global deep-water circulation to Earth's climatic change 135,000-107,000 years ago, Nature, 316, 505-507, 1985.

Foster, T. D., and E. C. Carmack, Temperature and salinity structure in the Weddell Sea, J. Phys. Oceanogr., 6, 36-44, 1976.

Gordon, A. L., and B. A. Huber, Thermohaline stratification below the southern ocean sea ice, J. Geophys. Res., 89, 641-648, 1984.

Hibler, W. D., A dynamic thermodynamic sea ice model, J. Phys. Oceanogr., 9, 815-846, 1979.

Hibler, W. D., Modeling a variable thickness sea ice cover, Mon. Weather Rev., 108, 1943-1973, 1980.

Hibler, W. D., The role of sea ice dynamics in modelling $\mathrm{CO}_{2}$ increases, in: Climate Processes and Climate Sensitivity, Geophys. Monogr. Serv.,vol. 29, edited by J. E. Hansen and T. Takahashi, pp. 238-253, AGU, Washington, D. C., 1984.

Hibler, W. D., and S. F. Ackley, Numerical simulation of the Weddell Sea pack ice, J. Geophys. Res., 88, 2873-2887, 1983.

Hibler, W. D., and K. Bryan, A diagnostic ice-ocean model, J. Phys. Oceanogr., 17, 987-1015, 1987.

Holt, T., P. M. Kelly, and B. S. G. Cherry, Cryospheric impacts on Soviet river diversion schemes, Ann. Glaciol., 5, 64-68, 1984.

Lemke, P., and T. O. Manley, The seasonal variation of the mixed layer and the pycnocline under polar sea ice, J. Geophys. Res., 89, 6494-6504, 1984.

Martinson, D. G., P. D. Killworth, and A. L. Gordon, A convective model for the Weddell polynya, J. Phys. Oceanogr., 11, 466-487, 1981.

McPhee, M. G., and J. D. Smith, Measurement of the turbulent boundary layer under pack ice, J. Phys. Oceanogr., 6, 696-711, 1976.
Niiler, P. P., and E. B. Kraus, One-dimensional models of the upper ocean, in Modelling and Prediction of the Upper Layers of the Ocean, edited by E. B. Kraus, pp. 143-172, Pergamon, New York, 1977.

Oort, A. H., Global atmospheric circulation statistics, 1958-1973, NOAA Prof. Pap. 14, 180 pp., U.S. Dep. Commerce, Rockville, Md., 1983.

Parkinson, C. L., On the development and cause of the Weddell polynya in a sea ice simulation, J. Phys. Oceanogr., 13, 501-511, 1983.

Parkinson, C. L., and W. M. Washington, A large-scale numerical model of sea ice, J. Geophys. Res., 84, 311-337, 1979.

Pollard, D., M. L. Batteen, and Y.-J. Han, Development of a simple upper-ocean and sea ice model, J. Phys. Oceanogr., 13, 754-786, 1983.

Shackleton, N. J., J. Imbrie, and M. A. Hall, Oxygen and carbon isotope record of east Pacific core V19-30: Implication for the formation of deep water in the late Pleistocene North Atlantic, Earth Planet. Sci Lett., 65, 233-244, 1983.

Shackleton, N. J., and N. G. Pisias, Atmospheric carbon dioxide, orbital forcing, and climate, in The Carbon Cycle and Atmospheric $\mathrm{CO}_{2}$ : Natural Variations Archean to Present, Geophys. Monogr. Ser., vol. 32, edited by E. T. Sundquist and W. S. Broecker, pp. 303-317, AGU, Washington, D. C., 1985.

Semtner, A. J., A model for the thermodynamic growth of sea ice in numerical investigations of climate, $J$. Phys. Oceanogr., 6, 379-389. 1976.

Semtner, A. J., On modelling the seasonal thermodynamic cycle of sea ice in studies of climatic change, Clim. Change, 6, 27-37, 1984a.

Semtner, A. J., The climatic response of the Arctic Ocean to Soviet river diversions, Clim. Change, 6, 109-130, 1984b.

Van Ypersele, J.-P., A numerical study of the response of the southern ocean and its sea ice to a $\mathrm{CO}_{2}$-induced atmospheric warming, Ph.D. dissertation, 146 pp., Fac. des Sci., Univ. Cath. de Louvain, Louvain la Neuve, Belgium, 1986.

P. Lemke, Max-Planck-Institut für Meteorolgie, Bundestrasse 55, D-2000 Hamburg 13, Federal Republic of Germany.

(Received November 29, 1986; accepted March 1, 1987.) 